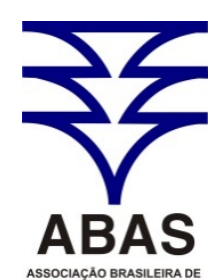

ASSOCIACAAO BRASILEIRADE
AGUAS SUBTERRANEAS www.abas.org

\section{ÁGUA SUSTENTÁVEL (AS): UM NOVO MÉTODO PARA A GOVERNANÇA DA ÁGUA}

\author{
SUSTAINABLE WATER (SW): A NEW METHOD FOR WATER \\ GOVERNANCE
}

\author{
Bruna Camargo Soldera ${ }^{1}$; Everton de Oliveira²;
}

DOI: http://dx.doi.org/10.14295/ras.v31i2.28650

Resumo: Partindo-se do pressuposto de que a degradação da qualidade da água pode ser objetivamente mensurável, assim como sua melhora de qualidade, este trabalho apresenta um novo conceito e método que permite a criação de instrumentos econômicos para gestão hídrica, este novo método é denominado Água Sustentável (AS). A simplicidade e força do método resumem-se no cálculo do volume de água necessário para se diluir uma massa qualquer de soluto até os padrões de potabilidade, ou qualquer outro padrão ecotoxicológico mais restritivo. Este método apoia-se inicialmente no conceito de Pegada Hídrica Cinza ou Água Cinza. Uma aplicação inicial foi realizada na sub- bacia hidrográfica do rio Jaguari, a escolha da área deve-se ao fato desta ser uma área com presença de indústrias de grande porte e intensa urbanização, contribuindo para pressão sobre os recursos hídricos. Os contaminantes selecionados para o cálculo da AS estão associados aos poluentes que podem atingir o manancial hídrico superficial e permanecer nele até a sua devida diluição, estes são DBO (Demanda Bioquímica de Oxigênio), Nitrato e Fósforo. Os resultados indicam que há uma carga de poluição excedente sendo lançada, uma vez que a AS calculada é muito superior à sua capacidade de diluição do rio, demonstrando deste modo, um excesso de massa de solutos no manancial hídrico.

Palavras-chave: Água Sustentável. Contaminação. Gestão de Recurso Hídrico.

Abstract: Assuming that the degradation of the water can be objectively measurable, so like its improve of the quality, this work presents a new concept and method that allows the creation of economic tools to water management, it is called Sustainable Water (SW). The simplicity and power this method is based on the calculation of the volume of water necessary to dilute a given mass of contaminant down to the drinking water standard or any other more restrictive ecotoxicological standard. The SW method relies on the principle originally established Grey Water Footprint concept (HOEKSTRA, 2009). Initial application was realized in the Watershed of River Jaguari, the choice of the area was due to large industrialization and urbanization, it contributed to pressure on water resources. The contaminants selected to the calculations of SW are associated with pollutants that can reach surface water and stay it until the dilution, they are BOD (Biochemical Oxygen Demand), Nitrate and Phosphorus. The results showed that there is a surplus load of pollution on the river and the river is incapable of dilute it.

Keywords: Sustainable Water. Contamination. Water Resource Management.

\section{INTRODUÇÃO}

Neste início de século XXI, no Estado de São Paulo em particular, e em outros Estados de forma geral, enfrentou-se uma séria crise hídrica. Vivencia-se um risco de desabastecimento, onde a demanda está cada vez maior e a oferta de água de qualidade é cada vez mais escassa. Esse é um panorama que deve ser agravado com a expectativa de aumento da população mundial e com o uso não sustentável da água que se faz hoje.

Sob esse aspecto, os recursos hídricos subterrâneos necessitam especial atenção dos órgãos ambientais e dos gestores públicos, pois são os grandes reservatórios

\footnotetext{
${ }^{1}$ UNESP/IGCE - Rio Claro/SP. E-mail: (brusoldera@hotmail.com)

${ }^{2}$ UNESP/IGCE - Rio Claro/SP. Hidroplan - Hidrogeologia e Planejamento Ambiental. E-mail: (everton@hidroplan.com.br)
} 
naturais de água do planeta e grande parte dos recursos hídricos superficiais são dai provenientes.

De acordo com Gleeson et al. (2015), existem 23 milhões de quilômetros cúbicos de água subterrânea em nosso planeta, porém meros 0,35 quilômetros cúbicos $(0,00015 \%$ ou $350.000 .000 \mathrm{~m}^{3}$ ) conseguem renovar-se em menos de 50 anos. Estas são as águas denominadas de águas subterrâneas modernas, que se encontram disponíveis para os mais diversos usos, porém são as mais suscetíveis às interferências das mudanças climáticas e à contaminação devido a atividades antrópicas (MERRITT \& KONIKOW, 2000; GLEESON et al., 2015).

Portanto, é imprescindível uma governança eficiente dos recursos hídricos subterrâneos, com gestão integrada aos recursos superficiais, e de modo a permitir o uso sustentável para as águas. A criação e desenvolvimento de métodos para combater a degradação dos recursos hídricos e gerar políticas racionais de uso é uma questão complexa devido aos processos envolvidos, e é também fundamental.

Assim, uma vez que a degradação da qualidade da água deva ser objetivamente mensurável, bem como sua melhora de qualidade, e os reservatórios subterrâneos necessitem ser reabastecidos para manutenção das quantidades de água disponíveis para uso dos seres vivos em geral, este trabalho apresenta um novo conceito que permite a criação de instrumentos econômicos para gestão hídrica, denominado Água Sustentável (AS).

Esta metodologia é marcada por sua simplicidade, podendo ser utilizada de forma ampla e sem qualquer complicação por governos, empresas, cidadãos e para quaisquer atividades humanas que envolvam o uso de água. A base do conceito da Água Sustentável é o cálculo do volume de água necessário para se diluir uma massa qualquer de soluto (contaminante) até o seu padrão de potabilidade, ou qualquer outro padrão ecotoxicológico mais restritivo. Apoia-se inicialmente no conceito de Pegada Hídrica Cinza ou Água Cinza (HOEKSTRA, 2009).
O desenvolvimento deste novo conceito e método (AS) expande o horizonte do conceito no qual se apoia (Água Cinza) e finalmente transcende-o, abrindo a possibilidade de estimativa e precificação do uso dos recursos hídricos em relação à sua degradação ou à melhora na sua qualidade, permitindo a criação de um mercado de créditos de água, à semelhança daquele criado para carbono. Assim, a AS poderá facilitar e promover usos sustentáveis dos recursos hídricos, servindo como base para governos melhorarem suas gestões.

Uma aplicação inicial deste novo método foi realizada na sub- bacia hidrográfica do rio Jaguari, uma sub- bacia formadora do rio Piracicaba, pertencente ao grupo de bacias organizadas administrativamente no denominado Comitê de Bacias PCJ (Piracicaba, Capivari e Jundiaí). A escolha da área deve-se ao fato desta ser uma área desenvolvida economicamente, com presença de indústrias de grande porte e intensa urbanização, contribuindo para pressão sobre os recursos.

\section{OBJETIVOS}

- Levantamentos, compilações e análise de dados sobre: qualidade do recurso hídrico; vazão do efluente lançado por diferentes atividades antrópicas; principais solutos que podem impactar de forma negativa o rio Jaguari;

- Cálculo das AS para cada um dos solutos que são frutos do efluente líquido proveniente das mais diversas atividades antrópicas na área estudada;

- Determinar o impacto causado ao recuso hídrico e, assim, propor soluções.

\section{PEGADA HÍDRICA FOOTPRINT)}

Contabilizar o uso que se faz da água no processo de produção de bens e serviços pode ajudar na compreensão dos efeitos que o 
comércio e o consumo têm sobre os recursos hídricos (CHAPAGAIN \& HOEKSTRA, 2008) e isto pode ser ferramenta importante para propor gestões e planejamentos mais eficientes. Esta é uma discussão que ganhou evidencia com o conceito de Pegada Hídrica (Water Footprint) proposto por Hoekstra em 2002 (HOEKSTRA, 2003).

A Pegada Hídrica é um indicador do uso direto e indireto da água doce, por pessoas, produtos, cidades, regiões e/ou países. Através do conhecimento do volume total da água utilizada no processo de produção de bens para consumo poderia se compreender os efeitos destes sobre os recursos hídricos. Além disso, permite obter informações temporais e espaciais do uso da água e então estimar o impacto ambiental, social e econômico que a produção e o consumo podem causar (HOEKSTRA, 2003).

A Pegada Hídrida se subdivide em três classes, sendo estas: a) a pegada hídrica azul que corresponde às águas superficiais e subterrâneas ao longo da cadeia de produção de produtos; b) pegada hídrica verde, a água de chuva armazenada no solo que é utilizada no processo de produção agrícola; e c) a pegada hídrica cinza, sendo esta o volume de

$$
P H_{c}=\frac{L}{C_{\max }-C_{\text {nat }}}[\text { volume } / \text { tempo }]
$$

Sendo $L$ a carga de poluente, $C_{\max }$ a concentração máxima permissível do contaminate no corpo hídrico e $C_{\text {nat }}$ é a concentração natural do corpo d’água receptor.

Se a Água Cinza for maior que zero, não significa necessariamente que a água tem sua qualidade degradada, mas sim que parte da capacidade do recurso em assimiliar os contaminantes foi consumida. Para verificar

$$
P h_{c}=\frac{L}{C_{\text {max }-C_{\text {nat }}}}=\frac{E f l x C_{e f l}-\operatorname{Capx} C_{c a p}}{C_{\text {max }}-C_{\text {nat }}}
$$

água doce necessária para diluir as cargas de poluentes existentes com base em padrões de qualidade ambiental (HOEKSTRA et al., 2009).

Está classificação pode auxiliar na compreenção de como o uso da água para a produção e consumo de bens interfere na qualidade do meio ambiente hídrico, de forma mais específica, levando em consideração o uso de cada classe de Pegada Hídrica. Destaca-se aqui a Pegada Hídrica Cinza, esta é um indicador de poluição hídrica e torna-se base para o desenvolvimento do nosso novo conceito e método denominado Água Sustentável.

\section{1 Pegada Hídrica Cinza}

A Pegada Hídrica Cinza também chamada de Água Cinza caracteriza-se por ser o volume de água necessário para absorver um ou mais poluentes até padrões de qualidade ambientais definidos pela legislação. Foi um conceito criado por Keller \& Keller (1995) e mais adinate aprimorado por Chapagain \& Hoekstra (2008). Para sua contabilização a seguinte equação foi proposta (Hoekstra et al., 2011):

se o rio pode ou não fazer a diluição dos contaminantes compara-se o valor da Pegada Hídrica Cinza com a vazão do corpo hídrico receptor ou com o fluxo de base das águas subterrâneas (HOEKSTRA et al.,2011).

Além disso, devem-se considerar as fontes pontuais e difusas de poluição. Nas fontes pontuais de poluição hídrica a carga de Água Cinza pode ser estimada da seguinte forma: 
Sendo que Efl é o volume de efluente, $C_{e f l}$ é a concentração do poluente no efluente, Cap é o volume de água captado e $C_{\text {cap }}$ representa a concentração de água captada.

Em fontes difusas de poluição a determinação não é fácil, pois a fração de substâncias químicas que atinge a água é de dificil medição, uma vez que não se tem a clareza de onde e quando medir (HOEKSTRA et al.,2011). Deste modo, é preciso estimar a Água Cinza através de modelos, estes modelos podem ser simples ou complexos, isto dependerá do objetivo do estudo e o grau de detalhe que se almeja.

Os estudos existentes sobre Pegada Hídrica Cinza se preocupam mais com o destino dela, ou seja, seu reúso, este pode ser em: sanitários, irrigação em jardins, campos de futebol e de golfe, cemitérios, parques, lavagem de veículos, utilização por bombeiros, em caldeiras, produção de concretos, entre outos usos (ERIKSSON et al., 2002). Mas quando se trata de sua origem as pesquisas encontradas na literatura ainda são escassaz.

\section{DEFINIÇÃO DO CONCEITO DE ÁGUA SUSTENTÁVEL}

A sustentabilidade é termo que está

$$
A S=\frac{M}{C_{m x}}[\text { volume }]
$$

Neste conceito todos os contaminantes provenientes das atividades antrópicas lançados nos corpos hídricos são fontes potenciais de contaminação. Desta forma, conceitualmente a AS é a água que potencialmente pode vir a se contaminar caso nenhuma ação seja tomada para remoção de massa de solutos e estes venham efetivamente a se diluir nos recursos hídricos até os valores cada vez mais presente nas mais variadas atividades antrópicas, a sua definição mais difundida é da Conferência de Brutland (World Commission on Environment and Development, 1987), a qual diz que o desenvolvimento sustentável ou a sustentabilidade deve satisfazer as necessidades das gerações presentes sem prejudicar as gerações futuras, ou seja, devese promover o uso racional dos recursos naturais para que todos possam deles usufruir.

Promover o uso sustentável dos recursos hídricos torna-se primordial, uma vez que a escassez da água e a degradação da sua qualidade interferem nos processos produtivos e na qualidade de vida, comprometendo o seu uso para gerações futuras.

A Água Sustentável (AS) é um novo conceito e método para medir a degradação dos recursos hídricos e propor a sua melhor utilização. É baseada no conceito de Pegada Hídrica Cinza, desenvolvido por Hoekstra et al. (2009).

Assim a AS é definida como o volume de água necessário (AS) para se diluir uma massa de contaminante $(M)$ presente no corpo hídrico até a concentração máxima aceitável definida pela legislação $\left(C_{\max }\right)$ ou padrão de potabilidade para consumo humano $(P)$, aquele que for mais restritivo:

$$
A S=\frac{M}{P}[\text { volume }]
$$

considerados $\left(C_{\text {máx }}\right.$ ou $\left.P\right)$.

Como o conceito de AS está sendo desenvolvido pioneiramente nesta pesquisa, não existem números precisos sobre o volume total da AS, mas pode ser facilmente demonstrável que o seu volume total é muito superior a toda a água disponível no planeta, uma vez que as atividades humanas acabam por disponibilizar grandes massas de solutos 
no meio ambiente e contribuem de maneira contínua para o aumento do volume de AS. A título de esclarecimento do conceito, nos parágrafos seguintes há alguns exemplos possíveis de cálculos de Água Sustentável (AS).

Hipoteticamente, assumindo-se que do total de 200.000 áreas potencialmente contaminadas existentes no Estado de São Paulo, correspondentes ao total de indústrias licenciadas pela CETESB que apresentam esse risco, 25\% estejam contaminadas. Assumindo-se adicionalmente uma média de $1 \mathrm{Kg}$ de contaminante conservativo (que não se degrada ou adsorve) por área cujo limite máximo aceitável fosse 100 microgramas por litro, teríamos deste modo um potencial de 500 milhões de metros cúbicos de água subterrânea potencialmente contaminável, ou seja o volume de água necessário para diluir este contaminante (AS) seria o equivalente a 500 milhões de metros cúbicos de água. Isso corresponderia a 1,4 vezes toda a água moderna calculada por Gleeson et al. (2015).

Outro exemplo é quando parte das águas da chuva são desviadas do seu caminho natural devido à impermeabilização da superfície natural do solo, e deixam de recarregar os aquíferos, fluindo superficialmente para um corpo d’água de qualidade inferior. Essa água de precipitação que deixa de se infiltrar (recarga) pode-se juntar a massas de contaminantes de várias origens que, diretamente ou por coletores de água pluvial, são transportados para rios. Essa água que se degradou no caminho e incorporou uma massa de soluto, e que ao ser dividida pelo valor de $C_{\max }$ ou $P$ desses contaminantes, permite chegar a volumes de AS realmente impressionantes. Impermeabilização de superfície é um fator de geração de AS.

O rebaixamento de lençol freático, seja para construções civis ou mesmo para agricultura, está água retirada escoa para rios e córregos, neste trajeto poderá levar consigo uma carga de contaminação proveniente das mais diversas atividades, gerando AS.

Indústrias de bebidas e alimentos utilizam uma grande quantidade de água em seus processos produtivos, e isto dá origem a um significativo volume de água residuária, que muitas vezes são lançadas na natureza sem o adequado tratamento. Da mesma forma as indústrias de papel e celulose, e cerâmicas e olarias também contribuem para o aumento das AS.

Somado a tudo isto, há ainda a água utilizada para limpeza, estas que contêm além dos resíduos contaminantes das indústrias, produtos para limpeza e desinfecção, e esta água em sua grande parte escoa sem tratamento até encontrar o recurso hídrico superficial ou infiltrar.

Estes resíduos incorporados à água irão necessitar de volumes cada vez maiores de água para sua diluição até a mínima condição ambiental adequada. Os exemplos são muito numerosos e todos podem ter suas AS calculadas.

Esse raciocínio utilizado nos exemplos nos permite visualizar a estimativa da quantidade de massas de solutos e como impactam o corpo hídrico, que vem a ser o próprio conceito de AS.

A AS difere-se do conceito da Pegada Hídrica Cinza, no qual se baseia, por ser mais restritiva em relação a condições ambientais. Na Pegada Hídrica Cinza, a carga ou massa de poluente no corpo hídrico $(M)$ é divida pela concentração máxima permissível desse poluente $\left(C_{\max }\right)$ subtraída da concentração natural do corpo d'água receptor $\left(C_{n a t}\right)$. No caso da AS a divisão é sempre pelo termo mais restritivo, ou seja, utilizou-se a $C_{\max }$ e o $P$, quando o termo mais restritivo é a $C_{\max }$ opta-se por dividir a carga de poluente por ele, caso contrário a usa-se o $P$, outro aspecto importante é que a AS permite o lançamento de a água em outras bacias, e isto não é possível pelo conceito de Pegada Hídrica.

Além de a AS ser mais ampla em relação às fontes de contaminação do que a Pegada Hídrica Cinza que considera como fonte de poluição da água somente a água proveniente de pia de banheiro, chuveiro e máquina de lavar para atividades domésticas, já para contaminantes agrícolas que podem atingir a água são considerados nitrato e 
fósforo (ERIKSSON et al., 2002; ENVIRONMENT AGENCY, 2011). Porém quando se fala em água cinza proveniente de indústria há uma grande lacuna de informações.

Outro aspecto importante que as AS enfatiza-se é em relação às águas subterrâneas. Muitas atividades utilizam para a produção de seus bens água proveniente de aquíferos, e estas águas que muitas vezes são exploradas com as melhores qualidades não retornam para o sistema subterrâneo, mas sim incorporam solutos que irão dar origem aos efluentes líquidos que terão como destino final o manancial hídrico superficial. Águas subterrâneas que muitas vezes têm sua qualidade modificada e no final do processo produtivo contribuem para o aumento das AS.

O tema é fundamental por ser um método de conservação dos recursos hídricos, permitindo seu uso da água de maneira sustentável. Contribuirá para melhor planejamento e gestão dos recursos hídricos, além de possibilitar a criação de um mercado de crédito hídrico.

\section{GESTÃO DOS RECURSOS HÍDRICOS}

Gestão e gerenciamento de recursos hídricos são termos que muitas vezes podem ser confundidos, mas possuem diferentes conotações. A gestão diz respeito a uma administração mais ampla de atividades, dentre as quais insere-se o gerenciamento.

A gestão abrange a política de recursos hídricos com diretrizes gerais, estruturação legal e institucional e um sistema gerencial, através do qual os diversos organismos envolvidos, sejam estes governamentais e/ou privados, possam elaborar e aplicar o planejamento de recursos hídricos (COSTA, 2008). Já o gerenciamento diz respeito a um conjunto de ações do governo voltadas à regulação e controle das águas, de acordo com normas da política de recursos hídricos.

A gestão é uma diretriz para auxiliar na resolução de problemas associados à escassez dos recursos hídricos e a má qualidade, devido a procedimentos de planejamento e administração (BARTH 1999 apud GRANZIERA, 2006).

No Brasil, a Lei Federal $n^{0}$ 9.433/1997 veio para promover a gestão sustentável e integrada dos recursos hídricos superficiais e subterrâneos.

No Estado de São Paulo a gestão de recursos hídricos origina das seguintes normas: Lei Estadual $\mathrm{n}^{\mathrm{0}}$ 6.134/1988, específica para a proteção das águas subterrâneas do estado, regulamentada pelo Decreto Estadual $n^{\circ} \quad 32.955 / 1991$; Lei Estadual $n^{0} 7.663 / 1991$, que orienta a Política Estadual de Recursos Hídricos e o Sistema Integrado de Gerenciamento de Recursos Hídricos; Decreto Estadual $n^{\circ} 41.258 / 1996$, que aprova artigos correlatos à Outorga de Direitos de Uso dos Recursos Hídricos; e as resoluções conjuntas SMA/SERHS n ${ }^{\circ} 1 / 2005$, integradora dos procedimentos de outorga e de licenciamento ambiental, e SMA/SERHS/SES $n^{\circ}$ 3/2006, que dispõe sobre procedimentos integrados para controle e vigilância sanitária de águas subterrâneas voltadas ao consumo humano, via soluções alternativas coletivas de abastecimento.

A Secretaria de Saneamento e Recursos Hídricos do Estado de São Paulo, na figura do Departamento de Águas e Energia Elétrica - DAEE é responsável pela gestão quantitativa das águas, já em relação aos aspectos de qualidade é responsabilidade da Secretaria Estadual do Meio Ambiente, através da Companhia Ambiental do Estado de São Paulo - CETESB.

Em relação às legislações que definem os padrões de qualidade de água e efluentes destaca-se a Resolução CONAMA $n^{0} 357$ de 2005 que dispõe sobre a classificação dos corpos d'água e diretrizes ambientais para o seu enquadramento, bem como estabelece as condições e padrões de lançamento de efluentes (BRASIL, 2005). Classifica as águas em 13 classes, sendo divididas em Águas Doces, Águas Salobras e Águas Salinas.

Na Seção II da Resolução CONAMA $\mathrm{n}^{0}$ 357, aborda através dos Artigos 14, 15, 16 
e 17 as condições e padrões de qualidade de água, classificam em valor máximo permitido nos corpos hídricos os parâmetros, parâmetros inorgânicos e orgânicos. As condições e padrões de lançamento de efluentes são referidos no Capítulo IV desta Resolução.

No ano de 2011, criou-se a Resolução CONAMA nº430, que dispõe sobre as condições e padrões de lançamento de efluentes, complementa e altera a Resolução n ${ }^{\circ} 357$ de 2005. A Seção II aplicase às condições e padrões de lançamento de efluente, apresentando valores que foram modificados da Resolução $n^{0} 357$, e a Seção III faz referência sobre as condições e padrões para efluentes de sistemas de tratamento de esgotos sanitários.

Em 12 de Dezembro de 2011, o Ministério da Saúde publicou a Portaria $\mathrm{n}^{\circ}$ 2914 que "dispõe sobre os procedimentos de controle e de vigilância da qualidade da água para consumo humano e seu padrão de potabilidade" (BRASIL, 2011). De acordo com Ribeiro (2012), os valores máximos permitidos para cada substância na água de acordo com a Portaria 2914 do Ministério da Saúde foram determinados com base na abordagem de avaliação quantitativa de risco químico, que permite aferir a concentração limite que, supostamente poderia ser ingerida continuamente ao longo de toda a vida sem risco considerável à saúde.

Gestão e gerenciamento são impor- tantes para a manutenção de um ambiente hídrico sádio, e devem ser executados em concordância. Gerir as águas superficiais e subterrâneas de modo integrado é necessário, uma vez que um sistema está interligado ao outro, e a degradação de um poderá afetar o utro. Assim ferramentas que auxiliem na gestão de qualidade e que vise a sustentábilidade do recurso são impressindíveis.

\section{MATERIAIS E MÉTODO}

\section{1 Área de estudo}

A região da Sub Bacia do Rio Jaguarí abrange 4 municípios do Estado de Minas Gerais e 15 municípios do Estado de São Paulo. A Bacia do Rio Jaguari estende-se por uma área de $3.290 \mathrm{~km}^{2}$, na Figura 1 pode-se visualizar a localização da sub- bacia.

$\mathrm{O}$ rio Jaguari tem como principal afluente o rio Camanducaia, e quando se junta com o Rio Atibaia formam o rio Piracicaba. Ao entrar em território paulista, o Rio Jaguari é represado, sendo este um dos reservatórios integrantes do sistema produtor de água chamado Cantareira (IRRIGART, 2005).

A sub-bacia do rio Juaguari encontrase em uma área bastante industrializada e urbanizada, o que contribui para pressão existente no recurso hídrico. 


\section{Área de Estudo}

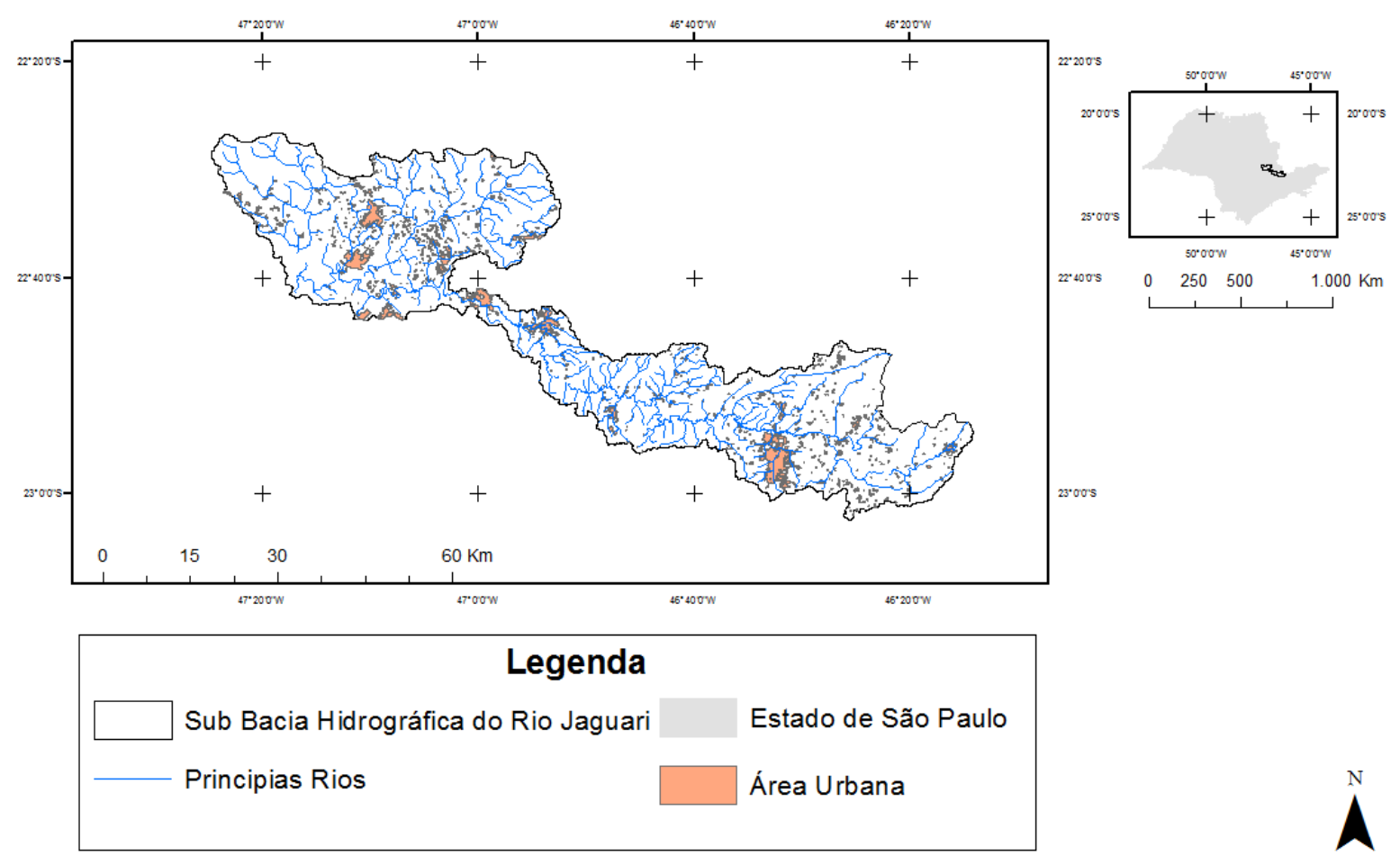

Figura 1 - Localização da Sub Bacia Hidrográfica do Rio Jaguari.

Figure 1 - Localization of Jaguari Hydrographic Sub Basins

\section{2 Levantamento e obtenção de dados}

O trabalho apresenta levantamentos, compilações, elaboração de bancos de dados, interpretações e análises para determinação das AS na sub- bacia do rio Jaguari.

Os dados foram obtidos em órgãos governamentais, sendo as principais fontes: CETESB (Agência Ambiental do Estado de São Paulo), DAEE (Departamento de Água e Energia Elétrica do Estado de São Paulo), ANA (Agência Nacional de Águas) e Comitê de Bacias Hidrográficas dos rios Piracicaba, Capivari e Jundiaí.

O objetivo foi calcular a AS para cada contaminante considerado que possa de algum modo impactar e causar desequilíbrio na qualidade da água superficial. As informações adquiridas para este objetivo foram:

- Empreendimentos domésticos, agrícolas e industriais que fazem parte da Bacia Hidrográfica do Rio Jaguari e que necessitam de outorga ou cadastramento para uso da água e lançamento de efluente no manancial hídrico. Estas informações são referentes a um banco de dados da Agência das Bacia Hidrográficas PCJ, ano de 2010. Devido à pouca informação e a dificuldade na sua aquisição, optou-se por trabalhar-se com o referido ano, uma vez que, mesmo com número reduzido de empreendimentos, os dados encontram-se completos, contendo todas as informações necessárias.

- Contaminantes que mais impactam a água superficial e seus limites de concentrações e padrões de potabilidade da água para consumo humano. Utilizou-se aqui a Resolução CONAMA n 357 de 2005, Resolução CONAMA no 430 de 2010 que definem as concentrações dos contaminantes na água, e a Portaria ${ }^{\circ} 2914$ referente ao ano de 2011 que define a qualidade e padrões de potabilidade da água para consumo humano.

- Vazão anual dos efluentes que estão sendo lançados nos corpos hídricos. Também se definiu em qual recurso hídrico está sendo efetuado o lançamento destes efluentes, 
considerando a eficiência de tratamento. Estes dados também foram adquiridos através do banco de dados da Agência das Bacias PCJ, ano de 2010.

- Vazão do rio. Os dados foram adquiridos através do banco de dados do DAEE (2016). A vazão aqui utilizada foi à vazão específica e através de sua área de contribuição pôde-se determinar as vazões em trechos que não havia dados.

- Enquadramentos em classes de rios. Os enquadramentos em classes de rios foram obtidos através do SIG PCJ (2016).

Os contaminantes selecionados estão associados aos poluentes que podem atingir o

$$
Q=\frac{V}{t} \quad \longrightarrow \quad V=Q \times t
$$

Onde, $Q$ é a vazão do efluente, $V$ o volume deste efluente, $t$ representa o tempo, $C$ a concentração e $M$ a massa do contaminante.

Após a obtenção dos resultados das massas dos contaminantes na água $(M)$, quantificaram-se as AS: dividindo a $M$ pela $C$ recomendável ou pelo $P$, dependendo do termo mais restritivo.

Estes resultados foram comparados com as vazões dos rios em cada trecho de lançamento de efluentes para verificar se a capacidade de diluição do recurso foi consumida e está gerando uma carga poluidora excedente.

Compara-se a AS com a vazão do rio, pois os tempos de lançamento do efluente e vazão do rio serão os mesmos e assim consegue-se saber se o volume do rio é capaz de diluir este efluente.

\section{RESULTADOS E DISCUSSÕES}

A Tabela 1 apresenta os resultados das AS para os solutos (ou indicadores) aqui estudados, os usuários localizados no Rio Jaguari, as classes de enquadramento do rio Jaguari e afluentes, além de suas vazões.

Os resultados indicam que há um excesso de massa fósforo (P), ou seja, este soluto requer mais água para diluição até padrões de qualidade ambiental. Percebe-se a manancial hídrico superficial e permanecer nele até a devida diluição, estes são DBO (Demanda Bioquímica de Oxigênio), $\mathrm{NO}_{3}^{-}$ (Nitrato) e P (Fósforo).

Após a aquisição e organização iniciaram-se os processamentos dos dados. Foram efetuadas a elaboração de bancos de dados e cálculos das AS para cada contaminante e considerando as classes dos rios. Para que isto fosse possível houve a necessidade de determinar a massa do contaminante no corpo hídrico. Uma vez em posse dos dados de vazões dos efluentes lançados nos rios, foi possível calcular a massa do poluente:

$$
C=\frac{M}{V} \quad \longrightarrow \quad M=C \times V
$$

AS para o contaminante P quando somado, é 1000 vezes superior à vazão do rio Jaguari.

É evidente que mesmo havendo tratamento dos contaminantes como previsto pela legislação, a carga de soluto ainda é alta e consequentemente as AS também.

Este trabalho propõe um uso mais sustentável para a água, assim uma vez que as leis não acompanham o comércio e o consumo, são necessárias gestões e fiscalizações mais eficientes e restritivas. A AS é um método rápido para obter informações sobre o estado do corpo hídrico e assim propor alternativas para sua conservação.

Outro aspecto importante é em questão a exploração da água subterrânea para a produção de bens, água que é retirada com boa qualidade, sofre degradação e posteriormente é lançada no corpo hídrico superficial. Está água além de ter impacto a sua qualidade também não retorna para o aquífero, sendo aqui gerados dois problemas, de qualidade e de quantidade.

Deste modo, para que haja um equilíbrio no ambiente hídrico, seriam necessárias técnicas de tratamento de efluentes mais eficientes, já em relação à quantidade, o déficit hídrico gerado deve-se ao fato do volume captado para produção de bens não ser o mesmo volume que é lançado, 
pois parte deste volume é embutido no produto final. Assim as atividades antrópicas desenvolvidas, seja na indústria, na agricultura ou mesmo em relação a atividades no setor doméstico, causarão sempre algum dano ao manancial hídrico (qualidade e/ou quantidade), por menor que seja.

Propor alternativas para solucionar estes tipos de problemas que afetam não só o ambiente hídrico, mas também social e economicamente, são necessárias e só poderão ser alcançadas por meio de melhores gestões e gerenciamentos, tanto em relação aos órgãos públicos que são responsáveis por criar as políticas públicas para serem implementadas na gestão hídrica, como também os setores privados, estes por meio de práticas que visem à sustentabilidade no uso da água. 
Tabela 1 - Águas Sustentáveis (AS) dos Contaminantes lançados pelos Empreendimentos localizados no Rio Jaguari e sua respectiva Classe de Enquadramento e Vazões Table 1 - Sustainable Water (SW) of Contaminants launched by Companies localized in the Jaguari river and it respective Framework Classe and River Flow (continua)

\begin{tabular}{|c|c|c|c|c|c|}
\hline & & & AS $\left(\mathbf{m}^{3}\right)$ & & \\
\hline USUÁRIOS & RIO & DBO & NITRATO & FÓSFORO & $\begin{array}{l}\text { VAZÃO DO } \\
\text { RIO (m³/ano) }\end{array}$ \\
\hline GLOBE QUÍMICA & JAGUARÍ (2) & $43.1 \mathrm{E}+3$ & $86.1 \mathrm{E}+3$ & $21.5 \mathrm{E}+6$ & $3.7 \mathrm{E}+6$ \\
\hline ALCEU PANEGASSI - ME & JAGUARÍ (2) & $2.2 \mathrm{E}+3$ & $4.3 \mathrm{E}+3$ & $1.1 \mathrm{E}+6$ & $3.7 \mathrm{E}+6$ \\
\hline FAGOR EDERLAN BRASILEIRA AUTO PEÇAS & JAGUARÍ (2) & $1.2 \mathrm{E}+3$ & $2.3 \mathrm{E}+3$ & $585.0 \mathrm{E}+3$ & $3.7 \mathrm{E}+6$ \\
\hline PREFEITURA MUNICIPAL DE PEDREIRA & JAGUARÍ (2) & $1.7 \mathrm{E}+6$ & $3.5 \mathrm{E}+6$ & $863.7 \mathrm{E}+6$ & $3.7 \mathrm{E}+6$ \\
\hline JOSÉ AUGUSTO FAVARO & JAGUARÍ (2) & $4.4 \mathrm{E}+3$ & $8.8 \mathrm{E}+3$ & $2.2 \mathrm{E}+6$ & $3.7 \mathrm{E}+6$ \\
\hline CANAÃ LAVANDERIA INDUSTRIAL LTDA. & JAGUARÍ (2) & $83.6 \mathrm{E}+3$ & $167.3 \mathrm{E}+3$ & $41.8 \mathrm{E}+6$ & $3.7 \mathrm{E}+6$ \\
\hline ISOLADORES SANTANA S.A. & JAGUARÍ (2) & $17.5 \mathrm{E}+3$ & $35.0 \mathrm{E}+3$ & $8.8 \mathrm{E}+6$ & $3.7 \mathrm{E}+6$ \\
\hline GELCO GELATINAS DO BRASIL LTDA & JAGUARÍ (2) & $876.0 \mathrm{E}+3$ & $1.8 \mathrm{E}+6$ & $438.0 \mathrm{E}+6$ & $3.7 \mathrm{E}+6$ \\
\hline $\begin{array}{l}\text { CONSTRUCAP - CCPS ENGENHARIA E } \\
\text { COMÉRCIO S.A. }\end{array}$ & JAGUARÍ (2) & $80.0 \mathrm{E}+0$ & $160.0 \mathrm{E}+0$ & $40.0 \mathrm{E}+3$ & $3.7 \mathrm{E}+6$ \\
\hline POSTO FRONTEIRA LTDA & JAGUARÍ (2) & $18.9 \mathrm{E}+3$ & $37.8 \mathrm{E}+3$ & $9.5 \mathrm{E}+6$ & $3.7 \mathrm{E}+6$ \\
\hline $\begin{array}{l}\text { COMPANHIA DE BEBIDAS DAS AMERICAS- } \\
\text { AMBEV }\end{array}$ & JAGUARÍ (2) & $4.4 \mathrm{E}+6$ & $8.8 \mathrm{E}+6$ & $2.2 \mathrm{E}+9$ & $3.7 \mathrm{E}+6$ \\
\hline
\end{tabular}


Tabela 1 - Águas Sustentáveis (AS) dos Contaminantes lançados pelos Empreendimentos localizados no Rio Jaguari e sua respectiva Classe de Enquadramento e Vazões Table 1 - Sustainable Water (SW) of Contaminants launched by Companies localized in the Jaguari river and it respective Framework Classe and River Flow (conclusão)

\section{USUÁRIOS}

COMPANHIA DE SANEAMENTO DE MINAS GERAIS - COPASA

COMPANHIA DE SANEAMENTO DE MINAS GERAIS - COPASA

PAPIRUS INDUSTRIA DE PAPEL S.A.

AJINOMOTO DO BRASIL INDUSTRIA E COMERCIO DE ALIMENTOS LTDA

COMPANHIA DE SANEAMENTO BÁSICO DO ESTADO DE SÃO PAULO

COMPANHIA DE SANEAMENTO BÁSICO DO ESTADO DE SÃO PAULO

ESPAN LAVANDERIA LTDA - ME

BARASCH INDÚSTRIA E COMÉRCIO DE PRODUTOS ELETRÔNICOS LTDA - EPP

BARASCH INDÚSTRIA E COMÉRCIO DE PRODUTOS ELETRÔNICOS LTDA - EPP

PREFEITURA MUNICIPAL DE ITAPEVA BENEDITO LUZIANO DE GODOY - ME

COMPANHIA DE SANEAMENTO BÁSICO DO ESTADO DE SÃO PAULO - PAULÍNIA

MELHORAMENTOS FLORESTAL S.A

Usuários

\section{RIO}

JAGUARÍ (2)

JAGUARÍ (2)

JAGUARÍ (2)

JAGUARÍ (2)

RIBEIRÃO LAVAPÉS (2)

RIBEIRÃO LAVAPÉS (2)

CÓRREGO DO MATO DENTRO (2)

RIBEIRÃO JUNCAL (2)

RIBEIRÃO JUNCAL (2)

CÓRREGO DA DIVINÉIA (2)

CÓRREGO DA GUARDINHA (2)

RIBEIRÃO DAS ANHUMAS (2)

RIBEIRÃO DOS PONCIANOS (2)

Rio

AS $\left(\mathbf{m}^{3}\right)$

DBO

$1.6 \mathrm{E}+6$

$1.6 \mathrm{E}+6$

$2.8 \mathrm{E}+6$

$8.4 \mathrm{E}+6$

$12.6 \mathrm{E}+6$

$160.8 \mathrm{E}+3$

$480.0 \mathrm{E}+0$

480.0E +0

480.0E+0

$454.1 \mathrm{E}+3$

$24.0 \mathrm{E}+3$

$74.6 \mathrm{E}+3$

$42.0 \mathrm{E}+3$

$76.7 \mathrm{E}+3$

$34.9 \mathrm{E}+6$
VAZÃO DO

RIO (m³/ano)

$3.7 \mathrm{E}+6$

$3.7 \mathrm{E}+6$

$3.7 \mathrm{E}+6$

$3.7 \mathrm{E}+6$

$3.7 \mathrm{E}+6$

$3.7 \mathrm{E}+6$

$3.7 \mathrm{E}+6$

$3.7 \mathrm{E}+6$

$454.1 \mathrm{E}+3 \quad 454.1 \mathrm{E}+3$

$24.0 \mathrm{E}+3 \quad 24.0 \mathrm{E}+3$

$74.6 \mathrm{E}+3 \quad 74.6 \mathrm{E}+3$

$3.7 \mathrm{E}+6$

$3.7 \mathrm{E}+6$

$3.7 \mathrm{E}+6$

$42.0 \mathrm{E}+3 \quad 42.0 \mathrm{E}+3$

$76.7 \mathrm{E}+3 \quad 76.7 \mathrm{E}+3$

$3.7 \mathrm{E}+6$

$3.7 \mathrm{E}+6$ 


\section{CONCLUSÃO}

Para que se possa alcançar um padrão sustentável necessita-se de grandes mudanças na gestão e conscientização de todas as partes, seja usuário direto como no caso de uma indústria e agricultura, ou usuário indireto, por exemplo, pessoas que consomem os bens e serviços destes setores.

O uso sustentável do recurso hídrico é também questão de saúde pública, uma vez que em um ambiente ambientalmente saudável a qualidade de vida melhora evitando doenças causadas através da ingestão ou contato com água de má qualidade.

Os cálculos das AS auxiliam em tomadas de decisões tanto no que diz respeito ao órgão gestor de recursos hídricos, como também para os setores industriais e agrícolas. Meios de produção que utilizem menor volume de água e tratamentos de efluentes de forma mais eficiente são importantes. Isso só vem a contribuir para utilização mais diligente e para o pensamento crítico sobre como fazer melhor e mais econômico uso da água.

Políticas que promovam a manutenção do equilíbrio tanto na exploração como na recarga de águas subterrâneas, são essenciais, além disso, propor alternativas para redução das AS são importantes do ponto de vista ambiental, econômico e social.

\section{REFERÊNCIAS}

BRASIL. Agências das Bacias PCJ Sistema de Informações Geográficas das Bacias PCJ. 2016. Disponível em: < https://sig.agenciapcj.org.br:9083/k2gisapp/ map>. Acesso em: 3 de abr. de 2016.

BRASIL. Comitê das Bacias Hidrográficas dos Rios Piracicaba, Capivari e Jundiaí. Disponível em: <www.comitepcj.sp.gov.br>. Acesso em: 04 de Mai. de 2016.

BRASIL. Agência Nacional de Águas: Sistema de informação Hidrológica. 2015. Disponível
$<$ http://hidroweb.ana.gov.br/default.asp> Acesso em: 13 de fev. de 2016.

CHAPAGAIN, A.K.; HOEKSTRA, A.Y. The global component of freshwater demand and supply: An assessment of virtual water flows between nations as a result of trade in agricultural and industrial products. Water International, v. 33, p. 19-32, 2008. Disponível em: $<$ http://www.utwente.nl/ctw/wem/organisatie /medewerkers/hoekstr a/chapagain hoekstra_2008.pdf $>$. Acesso em: 13 de fev. de 2016.

COSTA, W. D. Uso e gestão das águas subterrâneas. In: FEITOSA, F. A. C. et al. Hidrogeologia: conceitos e aplicações. 3. ed. Rio de Janeiro: CPRM/LABHID, 2008, p. 725-742.

ENVIRONMENT AGENCY. Grey water for domestic users: an information guide. 2011. Disponível em: < http://www.sswm.info/sites/default/files/re ference_attachments/ENVIRONMENT\%20 AGENCY\%202011\%20Greywater\%20for\% 20Domestic\%20Users.pdf $>$. Acesso em: 13 de fev. de 2016.

ERIKSSON, E.; AUFFARTH, K.; HENZE, M.; LEDIN, A. Characteristics of grey wastewater. Urban Water, v. 4, p. 85 -104, 2002. Disponível em: <http://ac.elscdn.com/S1462075801000644/1-s2.0-

S1462075801000644-

main.pdf?_tid=0513bffe-7f05-11e4-afe200000aacb35e\&acdnat $=1418062206$ af426c 48de2716c8bddcc72334964213>. Acesso em: 13 de fev. de 2016.

GLEESON, T.; BEFUS, K. M.; JASECHKO, S.; LUIJENDIJK, E.; CARDENAS, M. B. The global volume and distribution of modern groundwater. Nature Geoscience, v. 9, p.161-167, 2015. Disponível em; < http://www.nature.com/geosciences_marketi ng/index.html>. Acesso em: 20 de maio 2016. 
HOEKSTRA, A.Y. Virtual water trade: Proceedings of the International Expert Meeting on Virtual Water Trade. Value of Water Research Report Series, n.12, 2003, UNESCO-IHE. Disponível em: < http://www.waterfootprint.org/R eports/Report12. pdf $>$. Acesso em: 13 de fev. de 2016.

HOEKSTRA, A. Y.; CHAPAGAIN, A. K.; ALDAYA, M. M.; MEKONNEN, M. M. Water footprint manual: state of art. 2009. 127 p. Disponível em: $<$ http://www.waterfootprint .org/downloads/ WaterFootprintManual2009.pdf >. Acesso em: 13 de fev. de 2016.

IRRIGART - Engenharia \& Consultoria em Recursos Hídricos e Meio Ambiente Ltda. Relatório de Situação dos Recursos Hídricos das Bacias Hidrográficas dos Rios Piracicaba, Capivari e Jundiaí. Piracicaba - 2004 a 2006. Piracicaba, 2005. Disponível em: < http://www.com itepcj.sp.gov.br/download/ RS/RS-0406_Capitulo-2.pdf $>$. Acesso em: 12 de maio de 2016.

GRANZIERA, M. L. M. Direito de águas: disciplina jurídica das águas doces. 3. ed. São Paulo: Atlas, 2006.

KELLER, A.A., KELLER, J. Effective efficiency: a water use efficiency concept for allocating freshwater resources. In: Discussion Paper 22, Center for Economic Policy Studies, Winrock International, Washington DC, 1995. Disponível em: <
http://www.pacificwater.org/userfiles/file/IW RM/Toolboxes/WUE/Effective\%20Efficienc y\%20and\%20water.pdf $>$. Acesso em: 13 de fev. de 2016.

MERRITT, M. L.; KONIKOW, L. F. Documentation of a Computer Program to Simulate Lake-Aquifer Interaction Using the MODFLOW Ground-Water Flow Model and the MOC3D Solute-Transport Model. U.S. Geological Survey - Water-Resources Investigations Report 00-4167. 2000. Disponível em; < http://fl.water.usgs.gov/>. Acesso em: 20 de mai. 2016.

RIBEIRO, M. C. M. Nova Portaria de Potabilidade de Água: Busca de consenso para viabilizar a melhoria da qualidade de água potável distribuída no Brasil. Revista DAE, v. 1, n. 189, p. 8-15. 2012. Disponível em: $<$ http://revistadae.com.br/downloads/edicoes/ Revista-DAE-189.pdf $>$. Acesso em: 26 de fev. de 2016.

SÃO PAULO. Departamento de Água e Energia Elétrica do Estado de São Paulo. Disponível em: <http://www.hidrologia.daee.sp.gov.br/>. Acesso em: 13 de fev. de 2016.

World Commission on Environment and Development. Report of the World Commission on Environment and Development: Our Common Future. Oxford: Oxford University Press, 1987. Disponível em: http://www.un-documents.net/ourcommon-future.pdf. Acesso em: 13 de fev. de 2016. 